\title{
III. A comparison of the mercury unit with the British Association unit of resistance
}

\section{Cary T. Hutchinson \& Gilbert Wilkes}

To cite this article: Cary T. Hutchinson \& Gilbert Wilkes (1889) III. A comparison of the mercury unit with the British Association unit of resistance, Philosophical Magazine Series 5, 28:170, 17-29, DOI: $10.1080 / 14786448908619823$

To link to this article: http://dx.doi.org/10.1080/14786448908619823

Published online: 08 May 2009.

Submit your article to this journal $₫$

Џ Article views: 2

Q View related articles 5 
gences of the gold leaves were determined by an absolute electrometer, and the results are shown in fig. 1 (Plate I.).

It is probable that this valuable property of quartz, that it insulates perfectly in damp air, may be of use in the construction of electrostatic apparatus. The sulphuric acid now absolutely necessary in electrometers and instruments of that class is nothing short of a nuisance. If the instrument is carried about there is the risk of destruction of the instrument from the spilling of the acid. If the instrument is not moved the acid, unless specially treated, may give off nitrous fumes which will corrode the surfaces of metal; or, if forgotten, it absorbs water and in time overflows, destroying the whole apparatus. Even if the air were saturated with moisture, rods of quartz would insulate as well as the lead-glass at present used does in air dried by sulphuric acid. The needle should of course be suspended by a fibre of quartz, which is far simpler to apply and adjust than the double line of silk, and superior also in other respects.

In conclusion I must express my obligations to Mr. Briscoe, a student in the laboratory, whose skill in the manipulation of gold leaf and whose suggestions from time to time have been of the greatest service. I have with perfect confidence asked him to carry out the experiments described in this paper, and the results show that the confidence was not misplaced.

11I. A Comparison of the Mercury Lnit with the British Association Unit of Resistance. By CARY T. HUTCHINson and Gilbert Wilkes*.

THE object of this research, which was conducted in the Physical Laboratory of the Johns Hopkins University, under the supervision of Professor Henry A. Rowland, is the determination of the ratio of the resistance, at $0^{\circ} \mathrm{C}$, , of a column of mercury, 1 metre long and 1 square millimetre in cross section, to the British Association unit of electrical resistance.

The method employed in making the observations was, with slight modifications, the same as that used by Lord Rayleigh, by Glazebrook and Fitzpatrick, and also in a similar determination already made at this laboratory.

The resistance at $0^{\circ} \mathrm{C}$. of a column of mercury, filling a fine, accurately culibrated glass tube, is determined in British Association units ; the length $\mathrm{L}$ is known; its mean cross

* From the 'Johns Hopkins University Circular' for May 1889. Communicated by the Authors.

Phil. Mag. S. 5. Vol. 28. No. 170. July 1889. 


\section{Messrs. Hutchinson and Wilkes's Comparison of}

section at $0^{\circ} \mathrm{C}$. is found by weighing the volume of mercury, contained at that temperature, and dividing this by $\mathrm{L}$ multiplied by the density of mercury $(\rho)$ in grammes per cubic centimetre.

The resistance of a column of mercury of varying cross section is calculated as follows (Maxwell's 'Wlectricity and Magnetism') :-

Let $s$ be the cross section of the tube at a distance $x$ from one end ; let $\lambda$ be the length of a short thread of mercury, when its middle point is distant $x$ from this end ; then, assuming $s$ constant, throughout the length $\lambda$, we have $s=\frac{\mathrm{C}}{\lambda}$, where $\mathrm{C}$ is the constant volume of the thread.

The weight of mercury that fills the tube is

$$
\mathrm{W}=\rho \int s d x=\rho \mathrm{C} \Sigma\left(\frac{1}{\lambda}\right) \frac{\mathrm{L}}{n}, . . .
$$

in which $n$ is the number of points, at equal distances along the tube, where $\lambda$ is measured.

The resistance of the tube full of mercury is

$$
\mathrm{R}=\int \frac{r^{\prime}}{s} d x=\frac{r^{\prime}}{\mathrm{C}} \Sigma(\lambda) \frac{\mathrm{L}}{n}, \ldots . . .
$$

where $r^{\prime}$ is the specific resistance of mercury for unit volume. Hence, from (1) and (2),

or

$$
\mathrm{WR}=r^{\prime} \rho \Sigma(\lambda) \Sigma\left(\frac{1}{\lambda}\right) \frac{\mathrm{L}^{2}}{n^{2}}
$$

$$
r=\frac{10^{4} \mathrm{WR} n^{2}}{\rho \mathrm{L}^{2} \Sigma(\lambda) \Sigma\left(\frac{1}{\lambda}\right)},
$$

in which $r$ is the resistance of a column of mercury 1 metre long and 1 square millimetre in cross section, at $0^{\circ} \mathrm{C}$, expressed in British Association units.

In this equation put

$$
\frac{\Sigma(\lambda) \Sigma\left(\frac{1}{\lambda}\right)}{n^{2}}=\mu .
$$

The equation for $r$ now becomes

$$
r=10^{4} \frac{\mathrm{RW}}{\rho \mu \mathrm{L}^{2}} . \text {. . . . . . . . }
$$


the Mercury Unit with the British Association Unit.

$\mathrm{R}, \mathrm{W}, r, \rho, \mathrm{L}$ have already been defined. $\mathrm{L}$ is measured in centimetres ; Let

$\mu$ is the coefficient correcting for conicality of the tube.

$\mathrm{L}=$ length of tube at $t^{\prime \circ}$, measured by brass bar at $t_{6}{ }^{\circ}$;

$l=, \quad$ thread of mercury filling the tube at $0^{\circ}$, referred to bar at $t_{b}{ }^{\circ}$;

$\delta \mathrm{L}=$ correction to $\mathrm{L}$, for junction of column of mercury with terminals $=.82$ diameter of tube ;

$\rho=$ specific gravity of mercury at $0^{\circ} \mathrm{C} .=13.595$;

$y=$ cubic expansion of mercury per degree $=\cdot 0001795$;

$g=", \quad$ glass $" \quad "=000025$;

$b=$ linear " " bar " " $"=000019$;

$t_{0}=$ temperature "of brass bar, to which lengths are reduced, $=8^{\circ .7} \mathrm{C}$.

Then, volume of thread at $0^{2} \mathrm{C} .=\frac{\mathrm{W}}{\rho}$.

Mean section of tube at $0^{\circ}$

$$
\begin{aligned}
& =\frac{\mathrm{W}}{\rho} \frac{1}{l\left\{1+b\left(t_{b}^{\prime}-t_{0}\right)\right\}} \\
& =\frac{\mathrm{W}}{\rho} \cdot \frac{\left(1+\frac{1}{3} g t^{\prime}\right)}{\mathrm{L}\left\{1+b\left(t_{b}^{\prime}-t_{0}\right)\right\}} .
\end{aligned}
$$

Reduced length of tube at $0^{\circ}$

Hence

$$
=\frac{(\mathrm{L}+\delta \mathrm{L})\left\{1+b\left(t_{b}^{\prime}-t_{0}\right)\right\}}{1+\frac{1}{3} g t^{\prime}} .
$$

$$
\mathrm{R}=\frac{10^{-4} r \cdot \mu \cdot(\mathrm{L}+\delta \mathrm{L})\left\{1+b\left(t_{b}^{\prime}-t_{0}\right)\right\}}{1+\frac{1}{3} g t^{\prime}} \cdot \frac{\rho \mathrm{L}\left\{1+b\left(t_{b}{ }^{\prime}-t_{0}\right)\right\}}{\mathrm{W}\left(1+\frac{1}{3} g t^{\prime}\right)} .
$$

Solving for $r$,

$$
\begin{aligned}
r & =\frac{10^{4} \mathrm{RW}\left(1+\frac{1}{3} g t^{\prime}\right)^{2}}{\rho \mu \mathrm{L}(\mathrm{L}+\delta \mathrm{L})\left\{1+b\left(t_{b}^{\prime}-t_{0}\right)\right\}\left\{1+b\left(t_{b}^{\prime}-t_{0}\right)\right\}} \\
& =\frac{10^{4} \mathrm{RW}\left(1+\frac{1}{3} g t^{\prime}\right)^{2}}{\rho \mu \mathrm{L}^{2}}\left(1-\frac{\delta \mathrm{L}}{\mathrm{L}}\right)\left\{1-2 b\left(t_{b}{ }^{\prime}-t_{0}\right)\right\},
\end{aligned}
$$

or

$$
r=\frac{10^{4} \mathrm{RW}}{\rho \mu \mathrm{L}^{2}}\left(1-\frac{\delta \mathrm{L}}{\mathrm{L}}\right)\left(1+\frac{2}{3} g t^{\prime}\right)\left\{1-2 b\left(t_{b}^{\prime}-t_{0}\right)\right\} .
$$

The ends of the tube containing the mercury opened into the ebonite cups about two thirds filled with mercury. Upon the assumption that these may be considered infinitely large 
in comparison with the diameter of the tube, Lord Rayleigh has calculated that a correction of $\cdot 82$ diameter, additive to the true length of the tube, is necessary in order to allow for the resistance of the terminal connexions. Mascart, Nerville and Benoit, and also Glazebrook and Fitzpatrick have verified this result experimentally. This quantity is $\delta \mathrm{L}$ in the above formulæ.

In commencing our experiments in the spring of 1888 , our first object was to determine the best methods that had been used for the different determinations involved. About two months were spent in standardizing resistances that were to be used (the comparisons being made in a constant temperature vault, using a Fleming bridge) and in testing different methods of measurement.

An attempt to measure the lengths at $0^{\circ} \mathrm{C}$. was made, only the portion of the tube to be observed by the microscopes being scraped clear of ice. It was found that this method presented great difficulties; and as an error of 10 per cent. in the assumed expansion of glass, in reducing the length of the tube from $20^{\circ} \mathrm{C}$. to $0^{\circ} \mathrm{C}$., would only cause an error of ${ }_{1000000}^{16}$ in the length, the plan was abandoned.

The measurement of a column of mercury a little less than the length of the tube, which was covered with ice except at points over the ends of the column, was tried repeatedly, both by observing the meniscus and by flattening the ends of the mercury with hard rubber plugs (as suggested by Lord Rayleigh) without success. The lenses of the microscopes would naturally coat rapidly with moisture, and the unoccupied parts of the bore of the tube become so wet that minute globules of mercury would be left behind when the column was run out to be weighed. We endeavoured to obviate this by plugging the ends with soft wooden plugs; but still the moisture got in, making the meniscus uncertain, and interfering with the removal of the column.

Plate-glass end-pieces, held in place by elastic bands, were tried, hoping thus to obtain full tubes at $0^{\circ}$; but, owing to the grinding of the plates against the mouths of the tubes and the old trouble with wet mercury, these were given up.

The tubes were at first secured to straight, narrow, wellseasoned boards, and (the end-cups being in place) were put in watertight rectangular boxes (lined with waxed duck) about 5 inches wide and 5 inches deep. Crushed ice was then packed in over them. Though observations taken ten or fifteen minutes apart would apparently agree, it was found that, owing to the proximity of the board, the mercury would sometimes not have reached its minimum resistance in four 
or four and a half hours. The boards were therefore replaced by narrow partition-blocks, scored to allow the tubes to rest firmly. The tubes were thus raised about three quarters of an inch from the bottom of the box.

Most observers have measured the length of the column of mercury, used in determining the cross section of a tube, at the temperature of the room (between $10^{\circ}$ and $20^{\circ} \mathrm{C}$.), and then used a formula which reduces their observations to $0^{\circ} \mathrm{C}$. As the cubical coefficient of expansion of mercury in glass is .00016 , an error of little more than six tenths of a degree will make a difference of one part in ten thousand in the final result. Since the mercury-column is in a thick-walled glass tube, simply exposed to the air of the room (generally for a few hours), the uncertainty of its being at the temperature shown by thermometers placed alongside the tube may be readily seen. The tendency of this error will be to give too high a value for $r$. Glazebrook and Fitzpatrick measured the length of the column at intervals of fifteen minutes; and when two consecutive readings coincided, it was assumed that the mercury was at the temperature shown by the thermometers. They verified the result in several cases after the mercury had been blown out into a small capsule, but do not mention how they measured accurately the temperature of so small a volume of mercury.

In view of the results of our preliminary observations it was decided to determine the mean cross sections at zero, by using the mercury upon which the resistance-measurements had been made and obtaining a full tube as follows :-

When through with the resistance-measurements, one endpiece was removed and the tube stopped by one finger, over which was a tight, elastic, pure gum-band. The other end of the trongh was then raised to an angle of about $20^{\circ}$ without disturbing the tube in the ice, the end-piece quickly slipped off, the end of the mercury-column flattened off with a similarly covered finger, and any globules wiped away. The angle of the box being reversed, the mercury was allowed to flow out into a watch-glass, being afterwards dried over pumice-stone soaked with strong sulphuric acid.

Supposing that the exposed ends (about 6 centim. in all) rose to an average of $3^{\circ} \mathrm{C}$., which they could hardly do in the few minutes necessary to empty the tube, as they were in such close proximity to the ice, and the original temperature less than $0^{\circ} \cdot 3 \mathrm{C}$, the error due to this canse would make the result three parts in one hundred thousand too low.

Determination of $\mu$.- The tubes were furnished by Eimer and Amend, of New York, and out of a very large number 


\section{Messrs. Hutchinson and Wilkes's Comparison of}

about fifteen were selected on account of uniformity of bore, being tested by moving a small mercury column along in them and measuring its length with a scale. These were then more carefully tested and the best seven selected, which were cut as nearly as possible to represent exact multiples of a B.A. unit in resistance-one tube was cut for one half B.A. unit. The ends were ground convex, using a fine file and camphor in turpentine. After this the tubes were carefully cleaned, using distilled water, nitric acid, distilled water, ammonia, distilled water, alcohol, distilled water. Before using these liquids, a small piece of wet cotton-wool was drawn through the tubes (always in the same direction) in order to remove any solid particles that might accidentally be present. This was accomplished by first drawing through a silk thread by means of an air-pump, and then tying on the cotton and pulling it through several times in the same direction. This was always done in cleaning the tubes before filling. The tubes were dried by warm dry air, which had passed through calcium chloride and cotton-wool, the flow being kept up by a pneumatic pump.

The values of $\boldsymbol{\mu}$ for the different tubes were obtained by two independent determinations, using different lengths of the thread of mercary. The lengths of the thread were read on a dividing-engine.

TABLE I.-Values of $\mu$.

\begin{tabular}{|c|c|c|c|c|c|c|}
\hline Tube. & $\begin{array}{l}\text { Approximate } \\
\text { resistance. }\end{array}$ & $\boldsymbol{\mu}$ & $\begin{array}{l}\text { Length of } \\
\text { thread, in } \\
\text { centimetres. }\end{array}$ & $\mu$ & $\begin{array}{l}\text { Length of } \\
\text { thread, in } \\
\text { centimetres. }\end{array}$ & Mean $\mu$. \\
\hline II. & $\frac{1}{2} \frac{\text { ohm. }}{2}$ & $\begin{array}{l}1 \cdot 00056 \\
1 \cdot 00039\end{array}$ & $\begin{array}{l}5 \\
3\end{array}$ & $\begin{array}{l}1.00050 \\
1.00043\end{array}$ & $\begin{array}{l}39 \\
38\end{array}$ & $\begin{array}{l}1 \cdot 00053 \\
1 \cdot 00041\end{array}$ \\
\hline III. & 2, & 1.00088 & $4 \cdot 8$ & $\begin{array}{l}1 \cdot 00080 \\
1.00100\end{array}$ & $\left.\begin{array}{l}4 \cdot 0 \\
3 \cdot 5\end{array}\right\}$ & 1.00089 \\
\hline IV. & $\begin{aligned} 10 & \\
5 & \end{aligned}$ & $\begin{array}{l}1.00133 \\
1.00133\end{array}$ & $\begin{array}{l}3 \cdot 8 \\
4 \cdot 6\end{array}$ & $\begin{array}{l}1.00133 \\
1.00122\end{array}$ & $\begin{array}{l}4.8 \\
4.0\end{array}$ & $\begin{array}{l}1 \cdot 00133 \\
1 \cdot 00127\end{array}$ \\
\hline VI. & " & 1.00055 & $4 \cdot 7$ & $\begin{array}{l}1 \cdot 00063 \\
1 \cdot 00062\end{array}$ & $\left.\begin{array}{l}3.4 \\
3.8\end{array}\right\}$ & $1 \cdot 00060$ \\
\hline
\end{tabular}

Determination of L.-As all the tubes except one were longer than a metre we calibrated two metres of a five-metre bar; but it was found so unwieldy that better results could be expected from using a metre bar and three microscopes. Accordingly a comparator was placed on a long marble slab, and in prolongation with it a third microscope, mounted on a solid wooden block cemented to the slab, was placed. The values of the micrometer-divisions were respectively 0025 millim., $\cdot 0022$ millim., $\cdot 0045$ millim. 
Ebonite plugs were inserted in the ends, and readings were taken in at least four positions, by revolving the tube, in each measurement.

The temperatures of the tube under observation and bar were given by two thermometers lying against each. Measurements were made by both observers.

TABLE II.-Lengths of Tubes, in terms of brass Metre (by Bartels and Diederichs, Göttingen).

\begin{tabular}{|c|c|c|c|c|c|}
\hline Tube. & $\begin{array}{l}\text { Length, in } \\
\text { centimetres. }\end{array}$ & $\begin{array}{l}\text { Length, in } \\
\text { centimetres. }\end{array}$ & Average. & $\left|\begin{array}{c}\text { Temp. of } \\
\text { tube. }\end{array}\right|$ & $\begin{array}{c}\text { Temp. of } \\
\text { bar. }\end{array}$ \\
\hline $\begin{array}{l}\text { I. } \\
\text { II. } \\
\text { III. } \\
\text { IV. } \\
\text { V. } \\
\text { VI.* }\end{array}$ & $\begin{array}{r}127 \cdot 7599 \\
129 \cdot 8690 \\
\text { Broken in } \\
91 \cdot 4500 \\
181 \cdot 0100 \\
151 \cdot 0951 \\
151 \cdot 1049\end{array}$ & $\begin{array}{c}127 \cdot 7610 \\
129.8726 \\
\text { preliminary } \\
91 \cdot 4550 \\
181 \cdot 0147 \\
151 \cdot 1235 \\
151 \cdot 1034\end{array}$ & $\begin{array}{r}127 \cdot 761 \\
129 \cdot 871 \\
\text { work. } \\
91 \cdot 453 \\
181.012 \\
151.109 \\
151 \cdot 104\end{array}$ & $\begin{array}{l}19 \\
19 \\
19 \cdot 3 \\
24\end{array}$ & $\begin{array}{l}18 \cdot 5 \\
20 \\
18 \\
24\end{array}$ \\
\hline
\end{tabular}

The former value applies to determinations 1 and 2 of this tube, the latter to Nos. 3 and 4.

The temperature was very constant for the separate measurements on each tube and, as it never differed more than two degrees between corresponding observations, the average length is taken at the average temperature.

By comparison with the steel Rogers's standard, whose length is accurately known, the brass metre bar was found to equal $100 \cdot 031$ centim. at $25^{\circ} \mathrm{C}$; ; a result which agrees perfectly with previous determinations, using 000019 as the coefficient of linear expansion. This would make the bar correct at $8^{\circ} .7 \mathrm{C}$.

Weigling.-Schickert weights and balances were used, the former being compared with the glass standard kilogramme, which has been compared with the Berlin standard.

In order to avoid errors due to moisture and uncertainty as to temperature, the standard and weights compared were left standing on the scale-pans for several hours before taking the weighings, which were made without opening the case of the balances. The temperature was kept constant, barometer readings taken, and the air was kept dry by calcium chloride. The brass kilogramme $(\mathrm{K})$ was found to equal $1000 \cdot 001$ grammes in vacuo, which agrees well with former determinations. Specific gravity $8 \cdot 3$.

* One end became nicked and was smoothed off. 


\section{Messrs. Hutchinson and Wilkes's Comparison of}

Resistances. - The resistances used were :-

1. Warden-Muirhead 10 B.A.U., No. 292. Value, determined by Glazebrook, October 1887, 9.99416 at $16^{\circ} .5 \mathrm{C}$. Temperature-coefficient $\cdot 00292$. This coil was our standard.

2. Elliott 10 B.A.U., which has been several times compared at the Cavendish Laboratory. It is marked as found correct by Rayleigh at $20^{\circ} \cdot 9$. By comparison with W. M. No. 292, we found it correct at $20^{\circ} \cdot 8$. Temperature-coefficient $\cdot 0034$.

3. Elliott 1 B.A.U. Resistance .99950 at $16^{\circ} \mathrm{C}$. Temperature-coefficient $\cdot 00037$.

4. Pratt 1 B.A.U. Resistance 1.02579 at $16^{\circ} \mathrm{C}$. Temperature-coefficient $\cdot 00030$.

5. A circular comparator (designed by Professor Rowland), containing ten 10 B.A.U. coils wound together on a copper cylinder, which contained water. The coils are protected by an outer cylinder which leaves a large air-space. Contacts are made by means of mercury cups, arranged circularly in an ebonite top. This comparator was used in standardizing the one-ohm coils and as a shunt. The coils were always kept standing in water for several hours before being used, and the temperature of this water was kept perfectly constant throughout the day by having in each vessel a coiled lead pipe, which was connected by rubber tubing with the pipes of the city water-supply.

All resistances were compared both before starting and after completing this portion of the work, and the two sets of results agreed.

The resistance of the rods used to connect the end terminals to the bridge was calculated for temperature of room, $18^{\circ} \mathrm{C}$., .001257. By observation :-temperature of the room $21^{\circ} .5$, -001258. As this temperature never varied much from $22^{\circ}$, .00127 was used as the correction in all cases.

A Fleming bridge was used, and the value of a division of the bridge-wire by two distinet determinations gave agreeing results. The resistances were so combined (except in the case of the first measurements made) as to require the use of as small a portion of the wire as possible.

Tube I. was balanced against coils E 1 B.A.U. and P 1 B.A.U. in parallel, shunted by coils $1,2,3,5$ of comparator in series. In 1st observation, shunt $=$ coils $1+2$.

Tube II., against E 1 B.A.U. + P 1 B.A.v. in series, shunted by coils $2,3,4,5,6$ in series. In 1st observation, shunt $=$ coil 1 .

Tube III., broken in preliminary work.

Tube IV., against W.M. 10 B.A.U. 
Tube V., against W.M. 10 B.A.U. and E 10 B.A.U. in parallel. Tube VI., against E 1 B.A.U.

When coils were connected in parallel, their terminals rested solidly on copper disks, about $\frac{3}{4}$ inch in diameter, well amalgamated and covered with mercury, in boxwood cups. The rods connecting these cups to the bridge were short, stout copper rods, whose calculated resistance was .000156 at $16^{\circ} \mathrm{C}$. This is, of course, always taken into account.

After cleaning the tube as described above, each end was thrust through a perforated cork, which was then fitted into an end-piece similar to those used by Lord Rayleigh, and the outer surfaces of the corks were covered with melted paraffin. The mercury used was new and was distilled in a vacuum, the temperature of distillation being low. Before filling the tube, the mercury was gently warmed and was then poured into one of the end-pieces, the other end being raised, in order to allow the column to flow in slowly. If any specks or small bubbles were noticed on the sides of the bore of the tube, the filling was discontinued and the tube again cleaned. The terminal cups were about two thirds full of mercury. These were corked, the tube laid in the notched

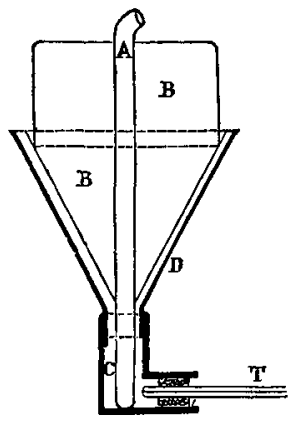

Scale $\frac{1}{\mathrm{E}}$.

A. Copper connecting Rod.

B. Ice cup.

C. Hard rubber terminal.

D. Hard rubber.

T. Tube.

partitions in the trough and well covered and surrounded with crushed ice. About four hours afterwards, the cups on the connecting rods (see figure) having been previously filled with ice, in order to have them cooled down before placing them in position, the resistance measurements were commenced and usually occupied about twenty minutes.

The galvanometer used was an Elliott, having a resistance of $1 \frac{1}{2} \mathrm{ohms.} \mathrm{A} \mathrm{difference} \mathrm{on} \mathrm{the} \mathrm{bridge-wire,} \mathrm{amounting} \mathrm{to}$ one part in 100,000 of the resistance, being measured gave readable deflexions on either side of the "balance" position.

Three complete sets of observations were always taken 
26 Messrs. Hutchinson and Wilkes's Comparison of

\begin{tabular}{|c|c|c|c|c|c|}
\hline : & 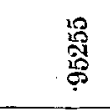 & 突 & 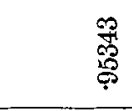 & $\begin{array}{l}\text { 总 } \\
\text { 号 }\end{array}$ & 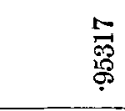 \\
\hline$\therefore$ & 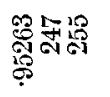 & 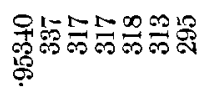 & 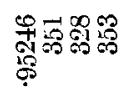 & 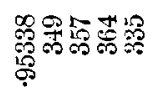 & 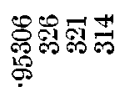 \\
\hline $\begin{array}{l}\dot{\vec{x}} \\
1 \\
1 \\
00 \\
\text { ज. } \\
1 \\
1\end{array}$ & $\begin{array}{l}: 8 \\
: 8 \\
\stackrel{8}{\circ}\end{array}$ & 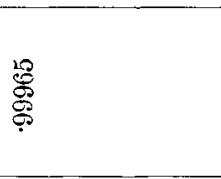 & 策 & 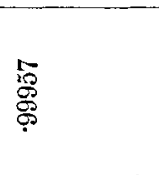 & 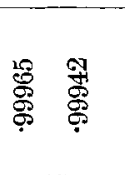 \\
\hline 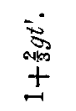 & 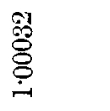 & 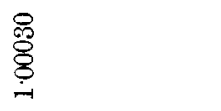 & 商 & $\begin{array}{l}1 \\
\stackrel{8}{8} \\
\stackrel{8}{8}\end{array}$ & 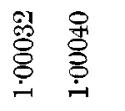 \\
\hline 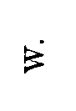 & 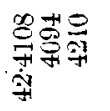 & 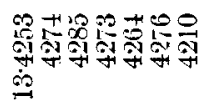 & 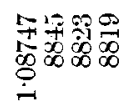 & 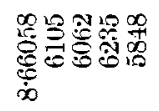 & 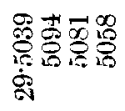 \\
\hline$\dot{1}$ & 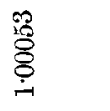 & $\begin{array}{l}\text { F्் } \\
\text { ह̊ }\end{array}$ & $\stackrel{9}{\stackrel{9}{8}}$ & 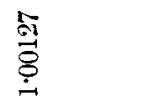 & 葛 \\
\hline$\underset{1}{1}$ & 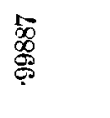 & 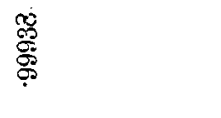 & 量 & 量 & $\begin{array}{l}\text { 落 } \\
\text { 官 }\end{array}$ \\
\hline$\therefore$ & $\stackrel{10}{9}$ & $\stackrel{\infty}{=}$ & $\begin{array}{l}\qquad 0 \\
\infty \\
-10\end{array}$ & 유 & $\stackrel{\infty}{\sim}$ \\
\hline$\ddot{\sim}$ & $\stackrel{-1}{-1}$ & $\stackrel{\infty}{=}$ & $\stackrel{2}{=}$ & $\stackrel{2}{=}$ & $\stackrel{9}{A}$ \\
\hline$\dot{4}$ & 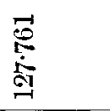 & 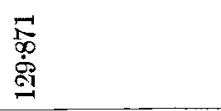 & $\begin{array}{l}\stackrel{9}{9} \\
\stackrel{9}{9}\end{array}$ & $\stackrel{\stackrel{9}{0}}{\stackrel{0}{0}}$ & 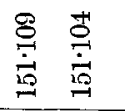 \\
\hline Aُ & 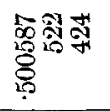 & 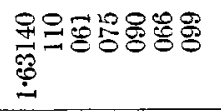 & 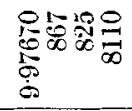 & 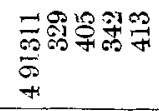 & 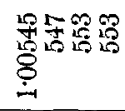 \\
\hline 离 & & & & & \\
\hline$\dot{0}$ & $\rightarrow \infty \in$ & - $+x=0+100$ & $-\cos 004$ & $-70100+10$ & $\tan 4$ \\
\hline$\underset{ت}{3}$ & $\mapsto$ & ヨ̈ & $\vec{E}$ & $\dot{D}$ & $\stackrel{-1}{5}$ \\
\hline & $-\infty \infty$ & tis ont- $\infty 000$ & $\Rightarrow$ 코곡 & 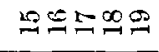 & ลลำ \\
\hline
\end{tabular}


the Mercury Unit with the British Association Unit.

and the current reversed, in order to eliminate any small thermal current.

Benoit has determined that the resistance of mercury is decreased by the diffusion of copper amalgam from the ends of copper connecting rods. Similar experiments, performed at this laboratory, have demonstrated the fact that, by leaving the rods dipping in the mercury in the end-pieces for twentyfour hours, the resistance was decreased one part in twentyfour hundred. Therefore, the decrease due to this cause in our investigations must be inappreciable.

In the cases of nine fillings, a small thermometer was placed in the mercury cups immediately after removing the rods. In no case was the temperature thus obtained greater than $1^{\circ} \mathrm{C}$., and the average of the nine sets of observations was $0^{\circ} .5 \mathrm{C}$. Supposing that 6 centim. of the tube were at this temperature, in the worst case the error would be $\cdot 00003$ high ; while, in the other cases, it would be about 00002 high.

Table III. (p. 26) gives our final results.

Owing to the tubes being entirely unprotected, great care was necessary in handling them. Tube III. was broken in our preliminary work, in trying to remove the end-pieces, which were then fitted with perforated rubber stoppers. These were after this replaced by common corks.

Tube I., whose bore was 1.76 millim. in diameter, allowed the soft rubber thimbles to sink into it and thus cause the column of mercury weighed to be smaller than it should have been. A correction should be applied on this account and might have been obtained by jacketing the tube with a waterjacket and then taking a number of alternating observations, using the thimbles and then glass plates. Unfortunately, this tube was broken after all the other observations had been completed. Its average-manifestly low-is not included in the tinal result.

Only one observation is neglected in the remaining tubesII., IV., V., VI. An error of one part in a thousand is apparent in observation No. 1 of tube IV., which is the case referred to.

In the final result there are, therefore, on

Tube II., 7 observations.

$\begin{array}{lcl}\text { IV., } 3 & \text { " } \\ \text { V., } 5 & \text { VI., } 4\end{array}$

Total . . 19 
28 Messrs. Hutchinson and Wilkes's Comparison of

Giving the tubes equal weights in the final average, we have :-

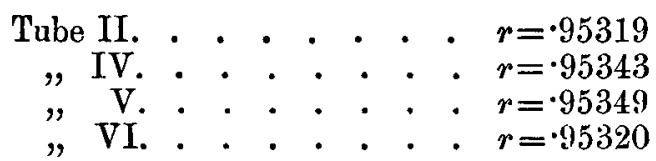

Mean . . $\overline{.95333}$

Arranging the tubes in the order of ratio of length to diameter, we have

TABLE IV.

\begin{tabular}{|r|c|c|c|}
\hline Tube. & Diameter. & $\begin{array}{c}\text { Ratio of length } \\
\text { to diameter. }\end{array}$ & $r$. \\
\hline I. & $\begin{array}{c}\text { millim. } \\
1.763\end{array}$ & 724 & .95255 \\
VI. & 1.352 & 1120 & .95317 \\
II. & .985 & 1320 & .95320 \\
V. & .670 & 2650 & .95349 \\
IV. & .334 & 2730 & .95343 \\
\hline
\end{tabular}

This table shows the effect of the sinking-in of the fingers, in taking the tubes full of mercury, for if we take tubes IV. and V., in which this ratio is roughly the same, the variations in $r$ may be due to other causes. So too, tubes II. and VI., in which this ratio is roughly the same, agree.

Observations were taken, as suggested above, to determine the correction for tube VI. The quantity obtained is a difference and, therefore, difficult to determine accurately. The results are given below :-

TABLE V.-Correction necessary in case of Tube VI., to reduce for sinking-in of fingers in taking full tube.

\begin{tabular}{|c|c|}
\hline Number of observation. & $\begin{array}{l}\text { Correction in } \\
\text { ró } 0 \text { of } 1 \text { per cent. }\end{array}$ \\
\hline 1 & +44 \\
\hline 2 & +23 \\
\hline 3 & +15 \\
\hline 4 & +28 \\
\hline Average & $=+27 \cdot 5=+00026$ \\
\hline
\end{tabular}




\section{Average obtained from Tube VI. $=\mathbf{9 5 3 1 7}$ Correction . . . . . $=000026$ \\ Corrected result from Tube VI. $=\cdot 95343$}

Taking the mean of tubes IV. and V., the variations of the other tubes are very nearly inversely proportional to the squares of these ratios.

Combining the results of tubes II., IV., V., VI., in this way, the final result would be $\cdot 95341$.

Combining the tubes with weights proportional to their resistances, that is proportional to $\frac{l}{d^{2}}$, the final result would be $\cdot 95341$.

Applying corrections, as given by Table V., we would have .95346 .

We therefore give, as our value of the resistance of a column of mercury one metre long, one square millimetre in cross section, at $0^{\circ} \mathrm{C}$.,

\section{$\cdot 95341$.}

TABLE VI.-Results obtained by different Experimenters.

\begin{tabular}{|c|c|c|c|}
\hline Observers. & Date. & References. & $\begin{array}{c}\text { Value of } 1 \\
\text { metre of } \\
\text { Mereury in } \\
\text { B.A.U. }\end{array}$ \\
\hline $\begin{array}{l}\text { Lord Rayleigh \& Mrs. Sidg- } \\
\text { wick }\end{array}$ & 1883 & Phil. Trans. 1883. & $\cdot 95412$ \\
\hline Mascart, Nerville \& Benoit & 1884 & Journal de Physique, 1884. & .95374 \\
\hline Strecker ......................... & 1885 & $\{$ Wiedemann's Annalen, & .95334 \\
\hline L. Lorentz....................... & 1885 & Same. & .95388 \\
\hline Rowland $\ldots . . . . . . . . . . . . . . .$. & 1887 & $\left\{\begin{array}{l}\text { Communicated to British } \\
\text { Association } 1887 \text {. } \\
\text { Abhandl. der } K \text { Bayer. }\end{array}\right.$ & .95349 \\
\hline Kohlrausch ...................... & 1887 & $\left\{\begin{array}{l}\text { Akad. der Wissenschat- } \\
\text { ten, II. Olasse, vol. xvi. } \\
\text { Abth. III. }\end{array}\right.$ & .95331 \\
\hline $\begin{array}{l}\text { Glazebrook \& Fitzpatrick... } \\
\text { Hutchinson \& Wilkes ..... }\end{array}$ & $\begin{array}{l}1888 \\
1888\end{array}$ & Phil. Trans. 1888. & $\begin{array}{l}.95352 \\
.95341\end{array}$ \\
\hline
\end{tabular}

